\title{
FACULTY-STUDENTS ONLINE COMMUNICATION CHANNELS
}

\author{
Hagit Meishar-Tal ${ }^{1}$ and Efrat Pieterse ${ }^{2}$ \\ ${ }^{1}$ Holon Institute of Technology, Israel \\ ${ }^{2}$ Western Galilee College, Israel
}

\begin{abstract}
In recent years, we have witnessed a significant expansion of the communication channels available to lecturers and students. The purpose of this study is to examine the considerations guiding faculty members in choosing the communication channels they offer their students and the connection between the communication channel chosen and personal and organizational characteristics. The study was conducted using a questionnaire distributed among lecturers through public distribution lists and social networks. A total of 128 respondents completed the questionnaire. It was found that the lecturers' use of the various communication channels available to them was conservative, i.e., the leading channels in use were formal communication (e-mail, face-to-face meetings, and course websites). The lecturers made very little use of personal communication channels and rarely used social media. It was also found that organizational climate, personality characteristics, and the perception of the lecturers' role were related to the use of personal and social communication channels.
\end{abstract}

\section{KEYWORDS}

Faculty-Students Communication, Out of Class Communication, Communication Channels, Social Networks, Course Site

\section{INTRODUCTION}

Over the past few years, there has been a significant increase in the use of digital media for communication purposes. This change challenges the student-faculty communication channels outside the classroom and raises questions about the boundaries, availability and students' access to faculty members. The purpose of this study is to examine the considerations guiding faculty members in choosing the communication channels they offer their students and the connection between the communication channel chosen and personal and organizational characteristics.

\section{FACULTY-STUDENT OUT OF CLASS INTERACTION}

In the past, informal interactions between students and lecturers took place primarily in the hallways of the academic institution and in face-to-face communications. In recent years, we have witnessed a significant expansion of the communication channels available to lecturers and students. These channels include e-mail, LMS communication tools such as forums, organizational communication systems, instant messaging, and social networks (Hoffman, 2014). Most of the research has focused on the importance of interpersonal and informal teacher-student communication for students and their impact on the learning experience, perseverance in studies, and even scholastic achievements (Lundberg \& Schreiner, 2004). As for the lecturers, they rarely initiate informal communication with their students (Cox et al., 2009; Einarson and Clarkberg, 2004).

Most of the applications made to lecturers by mail deal with the request to postpone assignments and questions about the learning content. In addition, there were differences between the organizations investigated in terms of the use of e-mail for lecturer-student communication. 
With the increasing use of social networks among students and lecturers, these channels began to serve as an additional platform for lecturer-student communication. Many faculty members are reluctant to establish informal Facebook communication with their students. This is mainly due to the fact that the information in this media is not compartmentalized and they are reluctant to expose the students to their personal lives (Abel, 2005, Hewitt \& Forte, 2006; Mendez et al., 2009). Nevertheless, exposing the teachers' private lives to their students through Facebook, and increased exposure of the lecturer to Facebook contributed to the student's perception of the lecturer as credible and human (Mazer et al., 2009; Sarapin, \& Morris, 2015).

In recent years, instant individual and group messaging, such as WhatsApp, which is widely used around the world, have become another popular tool of communication (Bouchnik \& Deshen, 2014). Using WhatsApp in academic courses has proven to contribute to student achievement and satisfaction (Davidovitch \& Yavich, 2016). Nevertheless, there are also challenges and problems using this channel for communication with students. WhatsApp is perceived as a channel of immediate response and so students have high expectations of lecturers' availability and response time. Conversely, lecturers are apt to be stressed and annoyed when receiving messages via this channel (Bouchnik \& Deshen, 2014).

In light of the changes in digital media channels in recent years, it is necessary to re-examine the attitudes that lecturers develop regarding the use of various media channels for informal communication outside class and the considerations that guide them in choosing the right media channel in different contexts and for different needs.

\section{METHODOLOGY}

\subsection{Research Questions and Research Tools}

The study was conducted using a quantitative, survey based methodology. A three-part questionnaire was distributed among lecturers and teaching staff in Israel. The questions relating to the demographic details of the respondents, their communication habits with their students, and the organizational climate were composed especially for this research. The questionnaire was first submitted to a small group of experts for validation and then distributed through a public mailing list of academics in Israel (SocSci-IL) and on social networks such as the Facebook page of Israeli academia (Academia-IL-Network)

The research questions are:

1. To what extent do lecturers use various online communication channels to communicate with students?

2. Is there a correlation between the extent to which the lecturers use various channels of communication and their perception of the role of lecturer?

3 . Is there a correlation between the extent to which teachers use different media channels and their perceptions of the organizational climate and policy of the institution in which they work?

\subsection{The Sample}

The questionnaire was distributed through a mailing list of Social Sciences academics (SocSci-IL) and was published on the Facebook group of the Academia-IL Network. A total of 128 respondents completed the questionnaire: $61 \%$ female and 39\% male. Average age- 46, average seniority-12 years, $66 \%$ were senior lecturers, $28 \%$ adjunct lecturer, $5 \%$ assistants and $1 \%$ Doctoral students.

\section{FINDINGS}

\subsection{Use of Communication Channels}

The lecturers were asked to rank their level of use of communication channels with students on a 1-5 Likert scale. Table 1 shows the amount of use of each communication channel divided into three groups.

Table 1 shows that the use of communication channels can be divided into three groups: formal communication (green), personal communication (orange), and social communication (blue). The ranking between the three groups is very clear, so that the formal channels were used most, the personal channels were used less and the least used was social media. 
Table 1. Use of Diverse Communication Channels

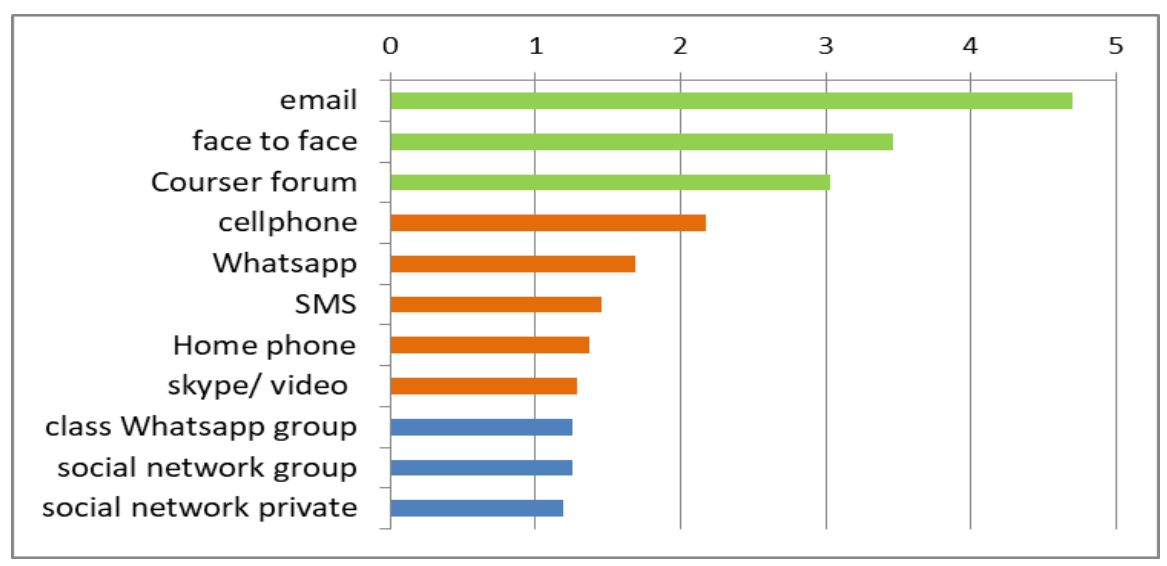

Formal communication: Formal communication was the main type used by faculty, leading with e-mail $(\mathrm{m}=4.70, \mathrm{SD}=0.60)$ followed by face-to-face communication $(\mathrm{m}=3.46, \mathrm{SD}=1)$. The use of the course forum as a means of formal communication was the lowest in the formal communication group $(\mathrm{m}=3.03$, $\mathrm{SD}=1.34$ ). An examination of the reliability of the formal media revealed that the three channels of communication cannot be considered as measuring the same variable. The Alpha Cronbach reliability value obtained was very low. Therefore, the analyses that follow relate to each formal channel as independent.

Personal communication: Personal communication was of low use only. The main use in this category was the personal mobile phone $(\mathrm{m}=2.17, \mathrm{SD}=1.13)$ followed by the private WhatsApp $(\mathrm{m}=1.69$, $\mathrm{SD}=1.04$ ). All five private channels were merged in to a new calculated variable of "personal communication" with an Alpha Cronbach reliability of 0.686 .

Social communication: Social media was the least and most rarely used by lecturers. All three private channels were merged in to a new calculated variable of "social communication" with an Alpha Cronbach reliability of 0.747 .

\subsection{The Correlation between the Perceptions of the Lecturer's Role and the Use of Communication Channels}

In order to examine the relationship between the perception of the lecturer's role and the degree of use of the various communication channels, the lecturers were asked to rate their agreement with a series of statements on a 1-5 Likert scale, some of which represent a perception of the lecturer's role as focusing on academic expertise and some on student service orientation (Table 2).

Table 2. Lecturers' Perception of the Their Role

\begin{tabular}{lll}
\hline Role Perception & $M$ & $S D$ \\
\hline Academic expertise centered, $\boldsymbol{\alpha}=\mathbf{0 . 6 6 5}$ & & \\
Be a role model for academic thinking & 4.75 & .47 \\
Provide information in my field of expertise & 4.66 & .55 \\
Guarantee a high level of academic learning & 4.66 & .54 \\
Motivate students to learning and research & 4.54 & .59 \\
Training quality professionals & 4.29 & .91 \\
Training future researchers & 4.03 & .94 \\
Average & $\mathbf{4 . 4 9}$ & $\mathbf{0 . 4 2}$ \\
\hline
\end{tabular}




\begin{tabular}{lcc}
\hline Role Perception & $M$ & $S D$ \\
\hline Student serving centered, $\boldsymbol{\alpha}=\mathbf{0 . 7 6 7}$ & & .83 \\
Support students with learning difficulties & 4.13 & .84 \\
Enable students to succeed in their studies & 4.11 & 1.04 \\
Give students the best service & 3.60 & .99 \\
Emotionally and intellectually support the students & 3.35 & 1.00 \\
Satisfy the students & 2.66 & $\mathbf{0 . 6 9}$ \\
Average & $\mathbf{3 . 5 7}$ & \\
\hline
\end{tabular}

Table 2 shows that the lecturers perceived their role as more focused on academic expertise $(\mathrm{m}=4.49, \mathrm{SD}=0.42)$ than on serving students $(\mathrm{m}=3.57 \mathrm{SD}=0.69)$. To examine the significance of the difference, a t-test for paired variables was performed, and a significant difference was found between the two roles $[\mathrm{t}(125)=15.21 \mathrm{p}<0.001]$.

In addition, a significant correlation was also found between the level of "role of serving the student" and the use of personal communication $(\mathrm{r}=0.277 \mathrm{p}<0.005)$ and also for use in social communication $(\mathrm{r}=0.203 \mathrm{p}<0.05)$. The more the lecturers perceived their role as focused on serving students, the more they enabled students to communicate with them through personal and social channels. No correlation was found between the perception of the role as an academic expert and the use of any communication channels.

\subsection{Correlation between Organizational Climate and Use of Communication Channels}

In order to examine the relationship between the level of use of different communication channels and the organizational climate, respondents were asked to rate their agreement with statements measuring organization atmosphere (for example: The atmosphere between lecturers and students is open and pleasant, the institution encourages informal communication with students) on a 1-5 Likert scale.

A significant correlation was found between the degree of use of personal communication and organizational climate $(r=0.224 \mathrm{p}<0.05)$, so that the more the organizational climate encourages personal connections between lecturers and students, the higher the level the use of personal communication channels. There was no correlation between organizational climate and other communication channels. E-mail was preferred in bi-directional and private communications.

\section{DISCUSSION}

As stated by Hoffman (2014), the benefits available to students as a result of their engagement with faculty outside class have been thoroughly examined, but missing from the literature is the faculty perspective on the use of different communication channels in various contexts (Hagenauer \& Volet, 2014). This study contributed to filling these lacunae. This study examined the communication channels lecturers use to communicate with students outside class. The lecturers' use of the various communication channels available to them was found to be conservative, i.e., the leading channels in use are formal communication (e-mail, face-to-face meetings, and course websites). E-mail leads as a preferred channel of communication, even more than face-to-face meetings. It is the leading preference for both bi-directional and private communications. The forum on the course website is only in third place and, as such, is used primarily for one-way and group communication but not for bi-directional interaction and personal communication. This finding raises questions about the success of academic institutions in assimilating the use of course forums.

Moreover, the lecturers make very little use of personal communication channels and rarely use social media. Despite studies showing that personal and social communication between teachers and students is beneficial to both parties (Lundberg \& Schreiner, 2004, Lambert, 2012), the lecturers communicate with 
students mainly through formal channels and the new media channels haven't yet fully penetrated the academic setting.

This study reveals two factors that are related to the lecturers' use of such communication: 1.Perception of the lecturer's role - the lecturer's perception of his/her role as focused on providing service to the student is also correlated positively with the extent to which personal communication is used. 2 . The organizational climate - It seems that the more the organizational climate encourages personal communication, the more the lecturers employ this type of communication. Future research will have to keep tracking the changes in communication channels used by lecturers with their students.

\section{CONCLUSION}

The changes in communication channels available to faculty and students outside the classroom complicates the decision about which channel to use very complicated This study shows that the lecturers are still very conservative in choosing the channels of communication with students and prefer formal communication over personal or social communication. Nevertheless, the diffusion of personal and social communication to this form of communication has begun and future studies will have to keep monitoring these changes.

\section{REFERENCES}

Bouhnik D and Deshen M (2014) WhatsApp goes to school: Mobile instant messaging between teachers and students. Journal of Information Technology Education: Research, 13, 217-231.

Cox BE, McIntosh KL, Terenzini PT, Reason RD and Quaye BRL (2010) Pedagogical signals of faculty approachability: Factors shaping faculty-student interaction outside the classroom. Research in Higher Education, 51(8), 767-788.

Davidovitch, N, Yavich R and Druckman, E (2016) Don't throw out paper and pens yet: On the reading habits of students. Journal of International Education Research, 12(4), 129-144

Einarson MK and Clarkberg ME (2004) Understanding faculty out-of-class interaction with undergraduate students at a research university. DigitalCommons@ILR. Cornell Higher Education Research Institute (CHERI) Retrieved 31 may 2017 from: http://digitalcommons.ilr.cornell.edu/cgi/viewcontent.cgi?article=1020andcontext=cheri

Hewitt, A., \& Forte, A. (2006). Crossing boundaries: Identity management and student/faculty relationships on the Facebook. Poster presented at CSCW, Banff, Alberta, 1-2. Hoffman EM (2014) Faculty and student relationships: Context matters. College Teaching, 62(1), 13-19.

Hoffman, E. M. (2014). Faculty and student relationships: Context matters. College Teaching, 62(1), 13-19.

Lambert AD, Rocconi LM, Ribera AK, Miller AL and Dong Y (2012) Faculty lend a helping hand to student success: Measuring student-faculty interactions. Association for Institutional Research 2012 Annual Conference. Recuperado de http://cpr.iub.edu/uploads/Faculty\%20Lend $\% 20 \mathrm{a} \% 20 \mathrm{Helping} \% 20 \mathrm{Hand} \% 20$ to\%20Student $\% 20$ Success $\% 20$ Measurin g\%20Student-Faculty\%20Interactions.pdf.

Lundberg CA and Schreiner LA (2004) Quality and frequency of faculty-student interaction as predictors of learning: An analysis by student race/ethnicity. Journal of College Student Development, 45(5), 549-565.

Mendez, J. P., Curry, J., Mwavita, M., Kennedy, K., Weinland, K., \& Bainbridge, K. (2009). To friend or not to friend: Academic interaction on Facebook. International Journal of Instructional Technology \& Distance Learning, 6(9), 33-47.

Sarapin SH and Morris PL (2015) Faculty and Facebook friending: instructor-student online social communication from the professor's perspective. The Internet and Higher Education, 27, 14-23. 